\title{
Discrimination against people with mental illness: what can psychiatrists do ${ }^{\dagger}$
}

\author{
Graham Thornicroft, Diana Rose \& Nisha Mehta
}

\begin{abstract}
SUMMARY
This article discusses the evidence that experiences of stigmatisation and discrimination among people with mental illnesses are common and may be severe. Furthermore, there are growing concerns that people with mental illness receive secondclass physical healthcare. Beyond this, some aspects of psychiatric practice are reported as being insensitive, disrespectful or even disabling. We consider whether such claims are justified and what psychiatrists can do, directly and indirectly, to reduce stigma and discrimination and improve our practice.
\end{abstract}

\section{DECLARATION OF INTEREST}

None.

Psychiatrists are specifically trained to do everything they can to help people with mental illness. So it comes as a shock to us, if not others, to realise that some of the people we intend to assist find that what we offer is at best a mixed blessing and at worst sometimes damaging. This article summarises the evidence that some people who have a mental illness try to avoid treatment and, if treated, report that they experience some aspects of mental healthcare (including contact with psychiatrists) as discriminatory. We go on to discuss ways in which psychiatrists can improve their practice in this regard.

\section{Avoidance of psychiatric treatment}

On what basis do people judge where to go for help for mental illness (Wang 2003)? A large national survey in Germany described vignettes of people with depression or schizophrenia and asked about how to find help (Angermeyer 1999). Revealingly, the general public thought that mental health staff are useful for treating schizophrenia, but not depression. The reason for this is that most people felt that schizophrenia is caused by biological or uncontrollable influences, whereas they understood depression to be a consequence of 'social disintegration' (including unemployment, drug or alcohol misuse, marital discord, family distress or social isolation). Consequently, people with depression were more often recommended to seek help and social support from a friend or confidant.

Even under better-resourced conditions, most people with a mental illness in the USA do not seek assistance. An early national US survey found that less than a third of all people with mental illness received assessment and treatment. The rate rose to $60 \%$ for people with a diagnosis of schizophrenia (Wang 2005). Indeed, over the past decade the occurrence of mental illnesses each year in the USA has not changed (the overall prevalence rate for all mental disorders was $29.4 \%$ in 1990 and $30.5 \%$ in 2001). By comparison, over the same period the proportion of people with mental illness that was treated rose from $20.3 \%$ to $32.9 \%$. Although this is a substantial increase in the proportion treated, the majority remained untreated.

Similarly, across Europe mental illness affects $27 \%$ of the population each year (Wittchen 2005), of whom $74 \%$ receive no treatment (Alonso 2007). By comparison, only $8 \%$ of people with diabetes mellitus do not receive care (Alonso 2007). A World Health Organization review of 37 studies across the world indicated the scale of this 'treatment gap' (Table 1). It is a paradox that even though two-thirds of adults with a mental illness (rated as 'emotional disorder' in the study by Kessler et al) went untreated, half of those who did receive
Graham Thornicroft is Professor of Community Psychiatry at the Institute of Psychiatry, King's College London, and a consultant psychiatrist and Director of Research and Development at the South London and Maudsley NHS Foundation Trust. Diana Rose is a senior lecturer

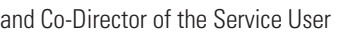
Research Enterprise, Institute of Psychiatry, which conducts serviceuser led research in the field of mental health. Professor Thornicroft and Dr Rose are also members of the National Institute for Health Research Biomedical Research Centre at the South London and Maudsley NHS Foundation Trust/ Institute of Psychiatry, and are supported by the NIHR Sapphire Applied Research Programme. Nisha Mehta is a medical student at the School of Medicine, King's College London, and is undertaking research related to stigma, discrimination and mental health. Correspondence Professor Graham Thornicroft, Health Service and Population Research Department, Institute of Psychiatry, King's College London, De Crespigny Park, London SE5 8AF, UK. Email: graham.thornicroft@kcl.ac.uk

${ }^{\dagger}$ For a commentary on this article see pp. 60-62, this issue.

\section{TABLE 1 The 'treatment gap' in mental illness}

\begin{tabular}{|lc|}
\hline Condition & Proportion of people untreated, \% \\
\hline Schizophrenia & 32.2 \\
\hline Depression & 56.3 \\
\hline Dysthymia & 56.0 \\
\hline Bipolar disorder & 50.2 \\
\hline Panic disorder & 55.9 \\
\hline Generalised anxiety disorder & 57.5 \\
\hline Obsessive-compulsive disorder & 57.3 \\
\hline Alcohol misuse or dependence & 78.1 \\
\hline
\end{tabular}

Sources: Kohn 2004; Wittchen 2005; World Health Organization 2005. 
treatment did not have a clear-cut mental illness (Kessler 2005). Interestingly, the findings of these surveys do not support the idea that conditions that are less stigmatised (e.g. depression compared with schizophrenia) are those that are seen to be more treatable (Jorm 2005). No single factor is enough to explain complex patterns of help-seeking. Nevertheless, the weight of evidence suggests that even when there are no major financial barriers to care, many people minimise their contact with services or do not seek help in an attempt to avoid being labelled as mentally ill (Corrigan 2004a) or submitting to treatments that they see as untherapeutic.

\section{Ethnic variations in help-seeking}

Certain groups may have even lower rates of treatment for mental disorders, in particular African Americans in the USA and Black Caribbean groups in the UK (McKenzie 2001; King 2005; Morgan 2006, 2007). Several US studies suggest that African Americans receive mental healthcare about half as often as White people (Cooper-Patrick 1999), even though they have higher rates of some mental disorders (Thornicroft 1999). Several important barriers to care can increase the impact of mental illnesses in Black communities in the UK and the USA. These factors have been described as: sociocultural (health beliefs and mistrust of services), systemic (lack of culturally competent practices in mental health services; Corrigan 2004b), economic (lack of health insurance) and individual (denial of mental health problems; Swanson 1995).

The interplay of these factors produces the contradictory situation in which Black groups may have higher rates of many mental illnesses, lower rates of general referral and treatment, but higher rates of compulsory treatment and contact with forensic services.

In the USA, patterns of contact with mental health services are in some ways different for Black and White people. Black people with a mental illness are more likely to seek help if their families are supportive and if a family member has had a positive personal experience of mental healthcare. In one study, African American interviewees did not view mental health on a continuum of well-being but tended to think of themselves as either mentally healthy or mentally ill. Many interviewees said that they did not think they were 'crazy', therefore they did not seek mental health services. Also, there was little information about mental health services in the African American community. Most people interviewed did not learn about available mental health services until their conditions had become severe (Davis 2004). There is an important general point here: most people of all cultures have relatively little accurate and useful knowledge about mental illness.

Aversion to psychiatric treatment, including preference for traditional or religious healers and ambivalence about (or at worst deliberate avoidance of) mental health services for fear of labelling and stigma, has been found throughout the world. For instance, a study of Muslim Arab female university students in Jordan, the United Arab Emirates and Israel found that for most of these women their first resort during times of psychological distress was to turn to God through prayer, rather than to seek help from health or social care agencies (Al-Krenawi 2004). A strong reluctance to be seen as mentally ill appears to be common wherever this has been studied.

\section{Why do some people avoid psychiatrists?}

Why do so many people try so hard to avoid contacting psychiatric services? People who are starting to have symptoms of mental illness are also members of the general population and share the same pool of information about psychiatric disorders. A number of common beliefs are likely to reduce their likelihood of seeking help: that psychiatric treatments are ineffective (Corrigan 2005a); that others will avoid them if their illness is revealed; and that individuals should solve their own problems (Kessler 2001). Even strong family encouragement to go for mental health assessment and treatment does not result in the person seeking help (Link 1989).

\section{The reputation of being a psychiatric patient}

For several decades it has been recognised that having been admitted to a psychiatric hospital can have an adverse effect on a person's reputation. This is evident, for example, in employment. It has to be acknowledged that to some extent low employment rates among people with mental disorders reflect real impairments that may limit some aspects of occupational role performance. In schizophrenia, for example, poor concentration can be a particular problem (Gold 2002). Even so, rates of employment among people with schizophrenia vary considerably between countries, so the primary impairment alone cannot fully explain such low work rates (Thornicroft 2004).

How can we understand the powerful blemish of being a psychiatric patient on a person's identity? In part, this damage is linked to popular views of psychiatrists: who they are, what they do and what they represent. It is widely believed that 
psychiatrists use diagnostic labels in a cavalier way (Sartorius 2002). Similarly, it is often believed that psychiatrists tend to use medications rather than psychological treatments and that these drugs have unpleasant or even dangerous side-effects.

\section{Professionals' perceptions of service users}

\section{Physician bias}

Is it possible that staff trained specifically to treat mental illnesses may contribute to the stigma that service users feel? The answer seems to be yes. A survey in South Australia, for example, compared the attitudes of more than 250 mental health staff and the general public about the likely outcomes of cases of people with depression and schizophrenia (Hugo 2001). Professionals were generally more pessimistic about the chances of recovery than the general public, and psychiatrists were even less optimistic than nurses. In an important observation, the study found that most staff base their attitudes on their personal experience of treating people with mental disorders.

This 'physician bias' is understandable, as doctors will tend to draw upon their own clinical experience when advising patients. ${ }^{\ddagger}$ In many specialist mental health services, the service users who recover quickly are discharged from care and so, over time, doctors tend to accumulate most of their clinical experience in trying to treat patients who do not fully recover or who recover and then relapse. They simply do not keep in touch with those who recover and stay well.

Perhaps an extreme version of this process applies to forensic psychiatrists, whose working life consists of assessing and treating mentally ill offenders, often people who have committed serious crimes. As a consequence, such psychiatrists tend to be even more cautious and pessimistic about therapeutic outcomes than general psychiatrists. Interestingly, in recent years a number of studies of schizophrenia have indicated that the long-term outlook for this condition is considerably better than previously believed (Murray 1999). An alternative explanation of these observations may be that mental health staff often feel a strong personal responsibility for doing everything that they can to prevent a relapse in the people they treat and so they are reluctant to encourage service users to take on potentially stressful activities, for example full-time work, in case the person's condition deteriorates (Murray 1999).

\section{Cinderella diagnoses}

People with certain mental disorders are often less welcomed for treatment by psychiatric staff, particularly people with a diagnosis of "personality disorder' (Department of Health 2003). Paradoxically, although service users with such a diagnosis claim to be particularly rejected by healthcare staff, there has been little research into this potential stigma. The few studies conducted do suggest that staff perceive people with this diagnosis to be difficult, less deserving of care, manipulative, attention-seeking, annoying and in control of their suicidal urges. The diagnosis is therefore interpreted by some mental health staff as pejorative and one that does not arouse their empathy.

Other diagnostic groups also appear to be less popular with healthcare staff. Chronic fatigue syndrome is bitterly contested in terms of its status as a physical, psychiatric or psychosomatic condition and arouses controversy about its causation and treatment. People who have been given or assumed this diagnosis often describe experiences of rejection by both general and mental health staff (Davidson 2005).

Another 'less deserving' category seems to be people with alcohol dependence. A British study used case vignettes to assess the influence of a past diagnosis of alcohol dependence on consultant psychiatrists' views about the treatment they would recommend (Corrigan 2005b). Participants were more likely to rate patients with a diagnosis of alcohol dependence as difficult, annoying, less in need of admission, uncooperative, having a poor prognosis and more likely to be discharged from follow-up.

A further group that appears to be less popular with general psychiatrists are people with a diagnosis of intellectual disability (also known as learning disability in UK health services) (Chaplin 2000).

The importance of such strong and rejecting prejudicial attitudes is that they can translate into discriminatory behaviour, for example in-patient unit staff or community mental health teams can set exclusion criteria for people with a diagnosis of personality disorder, so that it becomes a diagnosis of exclusion from care (Corker 2001).

\section{Professional pessimism}

Service users report that some general practitioners are even more often stigmatising than psychiatrists in responding unsympathetically to people with mental illnesses. A series of focus groups in England asked service users about their experiences of stigma and about who should receive targeted educational sessions to reduce discrimination. The group most often mentioned (by about twothirds of service users) was family doctors, closely followed by school children, employers and the
${ }^{\ddagger}$ Cognitive error and heuristics are explored in Crumlish N, Kelly BD (2009) How psychiatrists think. Advances in Psychiatric Treatment 15: 72-9. Ed 
${ }^{5}$ This topic is further discussed in Byrne P (2009) Why psychiatrists should watch films (or What has cinema ever done for psychiatry?). Advances in Psychiatric Treatment, 15: ???-???. Ed. police (Pinfold 2003a,b). This view is justified by the findings of a national survey in Australia that showed that family doctors and psychiatrists had more pessimistic views about the outcomes of mental illnesses than psychologists and the general public (Jorm 1999). The attitudes of psychiatric nurses were similar to those of psychiatrists, except that nurses were generally more positive about alternative and complementary approaches to treatment, such as vitamins, minerals and naturopathy.

\section{Stigma among medical students}

Negative attitudes can develop early. The findings of studies with medical students in several countries are far from reassuring (Wilkinson 1983a,b). In Croatia, for example, trainee doctors have been found to have stigmatising attitudes to mental illness, largely based on fear and ignorance (Filipcic 2003). Contact with people with mental illness is linked with more favourable attitudes among medical students, student nurses and occupational therapy students, although enduring and positive changes in such attitudes may be difficult to achieve.

Wilkinson et al found that medical students also had clear preferences for particular categories of patients and were less sympathetic towards those whom they believed to be undeserving of treatment because they were 'responsible' for their condition, for example people with eating disorders. One effect of these inaccurate and negative views about people with mental illness is that relatively few medical students choose psychiatry as a career. There is evidence that psychiatry is attracting fewer medical graduates, with associated shortages of qualified doctors in some high-income countries. As a result, there is a 'brain drain' of psychiatrists from lower-income countries, who move to richer nations, leaving their own countries even further depleted of staff.

\section{Dehumanisation of service users}

The core concern in mental health service users' reports of discrimination is dehumanisation (Corrigan 2005a). Time and again, service users describe being spoken to as if they were children, being excluded from important decisions, and being assumed to lack capacity to be responsible for their own lives. Other recurrent themes in service users accounts are being given insufficient information about their condition and treatment options, and feeling that behind many encounters with psychiatric staff is the usually unspoken threat of coercive treatment (Szmukler 2001; Ucok 2004; Chamberlin 2005).

\section{Stigma against mental health staff}

Although of relatively less importance than the discrimination against people with a mental illness, mental health staff are also subjected to a form of 'stigma by association'. As a psychiatrist, I (G.T.) am astonished by what most people think I do at work. Common views are that: psychiatrists 'have $\mathrm{X}$-ray vision'; can 'see into people's minds'; 'read other people's thoughts'; spend most of their time 'analysing' hypochondriacs who lie on couches; tend to be bearded (most psychiatrists in the UK are now women!); and are suspected of being somewhat eccentric if not mentally unbalanced themselves ('trick cyclists'). The limited work that has examined these curious views suggests that they largely stem from portrayals in the cinema (Byrne 2004).§

This stigma may have more sinister consequences for mental health staff and students. There is evidence, for example, that they receive worse treatment than members of the general public if they themselves become mentally ill (Repper 2003). There are strong and deep currents running among professionals here. One aspect of what has been called the 'helper syndrome' is that those providing care feel that there is a categorical difference between themselves (as well individuals, examples of health) and those whom they treat (who are sick, weak and dependent). To some extent, one advantage of such beliefs is that they allow staff to cope with the emotionally demanding work they face. But on the other hand, these views are dysfunctional when it comes to adjusting to mental illness when it affects them or their colleagues.

\section{Physical healthcare of service users}

If the attitudes of staff within mental health services are problematic, is the situation any better when people with mental illnesses also need treatment for physical health problems? If anything, the situation may be even worse. There is strong evidence that people with a diagnosis of a mental illness have less access to primary healthcare and receive inferior care for diabetes and heart attacks (Druss 2001). This is despite the fact that rates of physical illness and poor dental health among people with severe mental illness are much higher than in the general population (Phelan 2001), with especially high levels of cardiovascular disease, obesity, diabetes and HIV/ AIDS (Rethink 2005). This combination of high rates of physical illness and low rates of receiving effective treatment leads to the fatal consequences of discrimination and neglect: people with all types of mental disorder have an increased risk of premature death. 
The part of the general health system that seems to be most despised by many people with mental illness is the casualty or accident and emergency department (emergency room) (Disability Rights Commission 2006). The same themes occur repeatedly in service users' accounts. The first issue is that people who attend after harming themselves very often feel deliberately punished by staff and treated with a complete lack of respect. This relative neglect of the physical health of people with mental illness has been described as 'diagnostic overshadowing'.

\section{Choosing to stop contact with mental health services}

Perhaps not surprisingly, the single biggest factor that leads to stopping contact with mental health services, according to an Italian study, is dissatisfaction with the care received. When people with mental illness leave treatment before making a full recovery, their reasons may be particularly revealing. Generally speaking, it is people who are young, poor, single, uninsured or who have more than one diagnosis who are more likely to stop contact with services, even if they are still unwell when they take their own discharge (Rossi 2002). Interestingly, drop-out rates are higher for people who believe that psychiatric treatments are rarely effective, who are embarrassed to be seen by a mental health professional or who are prescribed medication without any psychological treatment. Surprisingly little has been written about why people stop attending appointments, from the point of view of service users themselves, either to understand what affects their satisfaction with care, to find out how stigma and discrimination play a role in these treatment decisions or to appreciate the mixed feelings that many people with mental illness have about their 'harmful healers' (Parkman 1997). One study of service users who had received electroconvulsive therapy found that those who felt damaged by the treatment subsequently avoided mental health services for fear that it would be prescribed again (Rose 2005).

\section{What can be done?}

If as psychiatrists we accept that some aspects of our treatment and care, seen from the perspective of services users, can have a negative impact on our patients' health, illness and holistic well-being, what can we do? Tables 2 and 3 summarise actions that might be taken, some by psychiatrists, some by other practitioners and some by agencies working in combination.

At the local level, specific targeted interventions may be important. A half of all UK employers think that none of their employees will have any

\section{TABLE 2}

Supporting individuals and family members to reduce stigma and improve practice

\begin{tabular}{|ll|}
\hline Action & By \\
\hline Develop new ways to offer diagnoses & Mental health staff \\
\hline $\begin{array}{l}\text { Have information packages for family members that explain the } \\
\text { causes, nature and treatments of different types of mental illness }\end{array}$ & $\begin{array}{l}\text { Mental health staff, } \\
\text { service users and families }\end{array}$ \\
\hline Actively provide factual information against popular myths & Mental health staff \\
\hline $\begin{array}{l}\text { Develop and rehearse accounts of mental illness experiences that } \\
\text { do not alienate other people }\end{array}$ & $\begin{array}{l}\text { Mental health staff and } \\
\text { service user groups }\end{array}$ \\
\hline
\end{tabular}

mental health problem in their working lifetime (Shaw Trust 2006). There is therefore a need both to inform employees about how common mental disorders are, and to make it clear that a mental illness diagnosis in itself has no implications for the employability of any particular individual. Landlords may need information on the facts about dangerousness to counteract their reluctance to lease/let their property. Judges and lawyers may benefit from education about how far people with mental illness are responsible and to blame for their conditions and on options for referral of individuals to mental health services. Local policy makers may well need to be informed if their financial allocations for mental healthcare show unintended systemic/structural discrimination against people with mental rather than physical disorders. Researchers need to establish whether the claim that smaller, community-based mental health centres are less stigmatising is true or not (Angermeyer 1987; Chee 2005).

\section{TABLE 3}

Reducing stigma and improving practice at the local level

\begin{tabular}{|c|c|}
\hline Action & By \\
\hline Introduce supported work schemes & $\begin{array}{l}\text { Mental health services with specialist } \\
\text { independent-sector providers }\end{array}$ \\
\hline $\begin{array}{l}\text { Offer psychological treatments to improve } \\
\text { cognition, self-esteem and confidence }\end{array}$ & Mental health and general health services \\
\hline $\begin{array}{l}\text { Give credit explicitly to applicants with a history } \\
\text { of mental illness when hiring staff in health and } \\
\text { social care services }\end{array}$ & Health and social care agencies \\
\hline $\begin{array}{l}\text { Provide reasonable adjustments/ } \\
\text { accommodations at work }\end{array}$ & $\begin{array}{l}\text { Mental health providers engaging with } \\
\text { employers and business confederations }\end{array}$ \\
\hline $\begin{array}{l}\text { Inform employers of their legal obligations } \\
\text { under disability laws }\end{array}$ & Employers' confederations \\
\hline $\begin{array}{l}\text { Deliver and evaluate the widespread } \\
\text { implementation of targeted interventions with } \\
\text { groups such as school children, police and } \\
\text { healthcare staff }\end{array}$ & $\begin{array}{l}\text { Education, police, and health commissioning } \\
\text { and providing authorities }\end{array}$ \\
\hline $\begin{array}{l}\text { Provide mental health practitioners with } \\
\text { accurate data on mental illness recovery rates }\end{array}$ & $\begin{array}{l}\text { Professional training and accreditation } \\
\text { organisations }\end{array}$ \\
\hline $\begin{array}{l}\text { Implement measures to support care plans } \\
\text { negotiated between staff and service users }\end{array}$ & $\begin{array}{l}\text { Mental health provider organisations and } \\
\text { service user groups }\end{array}$ \\
\hline $\begin{array}{l}\text { Improve systems to finance, train and support } \\
\text { mental healthcare staff }\end{array}$ & $\begin{array}{l}\text { Mental health service commissioner and } \\
\text { provider organisation }\end{array}$ \\
\hline
\end{tabular}

For more details see Thornicroft 2006a. 


\begin{tabular}{|lllll|}
\multicolumn{5}{|c}{ MCO answers } \\
1 & 2 & 3 & 4 & 5 \\
af & af & af & af & at \\
bf & bf & bf & bf & bf \\
cf & ct & cf & cf & cf \\
dt & df & dt & dt & df \\
ef & ef & ef & ef & ef
\end{tabular}

At the personal level there are a number of further actions that all mental healthcare professionals can take or avoid to work towards eradicating stigma and discrimination:

- appreciate that nihilistic pronouncements such as 'you will never work again' or 'you must not expect to have children' may have profoundly long-term and disabling consequences for service users;

- avoid 'totalising' terms such as 'schizophrenic': we would not refer to a person as a 'cardiac';

- avoid pessimistic terms such as 'chronic' schizophrenia;

- find out the extent to which service users feel empowered or disempowered by receiving a diagnosis or a treatment;

- assess the extent to which diagnostic information needs to be tailored to the needs of each person in terms of rationale and implications for care;

- involve service users more fully as active participants in a negotiation process to see whether this makes a diagnosis or treatment more acceptable;

- encourage service users to prepare for and take placements in mainstream or supported work schemes;

- actively contribute to news and features in the media to increase the public's factual knowledge about mental illnesses and their treatments;

- advocate for service users against examples of discrimination;

- understand the importance of involving service users in policy decisions relayed to diagnoses, for example in relation to welfare benefits or access to driving licences.

The findings outlined in this article suggest that the role of psychiatrists, in trying to offer and provide assistance to people with mental illnesses, is not necessarily straightforward and that we need to consider how we may inadvertently or indirectly contribute to disability rather than to recovery.

\section{Acknowledgement}

Elements of this article are from Thornicroft 2006a.

\section{References}

Al-Krenawi A, Graham JR, Dean YZ, et al (2004) Cross-national study of attitudes towards seeking professional help. Jordan, United Arab Emirates (UAE) and Arabs in Israel. International Journal of Social Psychiatry, 50: 102-14.

Alonso J, Codony M, Kovess V, et al (2007) Population level of unmet need for mental healthcare in Europe. British Journal of Psychiatry, 190: 299-306.

Angermeyer MC, Link BG, Majcher-Angermeyer A (1987) Stigma perceived by patients attending modern treatment settings. Some unanticipated effects of community psychiatry reforms. Journal of Nervous and Mental Disease: 175: 4-11.

Angermeyer MC, Matschinger H, Riedel-Heller SG (1999) Whom to ask for help in case of a mental disorder? Preferences of the lay public. Social Psychiatry and Psychiatric Epidemiology, 34: 202-10.
Byrne $\mathrm{P}$ (2004) Imagining the nineties. Mental illness stigma in contemporary cinema. In Every Family in the Land: Understanding Prejudice and Discrimination against People with Mental IIIness (ed AH Crisp): 110-7. Royal Society of Medicine Press.

Chamberlin J (2005) User/consumer involvement in mental health service delivery. Epidemiologia e Psichiatria Sociale; 14: 10-4.

Chaplin R (2000) Psychiatrists can cause stigma too. British Journal of Psychiatry, 177: 467

Chee CY, Ng TP, Kua EH (2005) Comparing the stigma of mental illness in a general hospital with a state mental hospital. A Singapore study. Social Psychiatry and Psychiatric Epidemiology, 40: 648-53.

Cooper-Patrick L, Gallo JJ, Powe NR, et al (1999) Mental health service utilization by African Americans and Whites. The Baltimore Epidemiologic Catchment Area Follow-Up. Medical Care; 37: 1034-45.

Corker E (2001) Stigma caused by psychiatrists. British Journal of Psychiatry, 178: 379

Corrigan PW (2004a) How stigma interferes with mental health care. American Psychologist, 59: 614-25.

Corrigan PW, Markowitz FE, Watson AC (2004b) Structural levels of mental illness stigma and discrimination. Schizophrenia Bulletin; 30: 481-91.

Corrigan PW (2005a) On the Stigma of Mental IIIness. American Psychological Association.

Corrigan PW, Lurie BD, Goldman HH, et al (2005b) How adolescents perceive the stigma of mental illness and alcohol abuse. Psychiatric Services; 56: 544-50.

Davidson J (2005) Contesting stigma and contested emotions. Personal experience and public perception of specific phobias. Social Science and Medicine; 61: 2155-64.

Davis S, Ford M (2004) A conceptual model of barriers to mental health services among African Americans. African American Research Perspectives; 10: 44-54.

Department of Health (2003) Personality Disorder No Longer a Diagnosis of Exclusion: Policy Implementation Guidance for the Development of Services for People with Personality Disorder. Department of Health.

Disability Rights Commission (2006) Equal Treatment. Closing the Gap. A Formal Investigation into Physical Health Inequalities Experienced by People with Learning Disabilities and/or Mental Health Problems. Disability Rights Commission

Druss BG, Bradford WD, Rosenheck RA, et al (2001) Quality of medical care and excess mortality in older patients with mental disorders. Archives of General Psychiatry, 58: 565-72

Filipcic I, Pavicic D, Filipcic A, et al (2003) Attitudes of medical staff towards the psychiatric label "schizophrenic patient" tested by an antistigma questionnaire. Collegium Antropologicum; 27: 301-7.

Gold JM, Goldberg RW, McNary SW, et al (2002) Cognitive correlates of job tenure among patients with severe mental illness. American Journal of Psychiatry, 159: 1395-1402.

Hugo M (2001) Mental health professionals' attitudes towards people who have experienced a mental health disorder. Journal of Psychiatric and Mental Health Nursing: 8: 419-25.

Jorm AF, Korten AE, Jacomb PA, et al (1999) Attitudes towards people with a mental disorder. A survey of the Australian public and health professionals. Australian and New Zealand Journal of Psychiatry, 33: 77-83.

Jorm AF, Christensen H, Griffiths KM (2005) The impact of beyondblue. The national depression initiative on the Australian public's recognition of depression and beliefs about treatments. Australian and New Zealand Journal of Psychiatry, 39: 248-54.

Kessler RC, Berglund PA, Bruce ML, et al (2001) The prevalence and correlates of untreated serious mental illness. Health Services Research; 36: 987-1007.

Kessler RC, Demler 0, Frank RG, et al (2005) Prevalence and treatment of mental disorders, 1990 to 2003. New England Journal of Medicine; 352: 2515-23.

King M, Nazroo J, Weich S, et al (2005) Psychotic symptoms in the general population of England. A comparison of ethnic groups (The EMPIRIC study). Social Psychiatry and Psychiatric Epidemiology, 40: 375-81. 
Kohn R, Saxena S, Levav I, et al (2004) The treatment gap in mental health care. Bulletin of the World Health Organization; 82: 858-66.

Link BG, Cullen FT, Struening EL, et al (1989) A modified labeling theory approach in the area of mental disorders. An empirical assessment. American Sociological Review, 54: 100-23.

McKenzie K, Samele C, Van Horn E, et al (2001) Comparison of the outcome and treatment of psychosis in people of Caribbean origin living in the UK and British Whites. Report from the UK700 trial. British Journal of Psychiatry, 178: 160-5.

Morgan C, Dazzan P, Morgan K, et al (2006) First episode psychosis and ethnicity. Initial findings from the AESOP study. World Psychiatry, 5: $40-6$

Morgan C, Fearon P (2007) Social experience and psychosis insights from studies of migrant and ethnic minority groups. Epidemiologia e Psichiatria Sociale; 16: 118-23.

Murray MG, Steffen JJ (1999) Attitudes of case managers toward people with serious mental illness. Community Mental Health Journal; 35: 505-14.

Parkman S, Davies S, Leese M, et al (1997) Ethnic differences in satisfaction with mental health services among representative people with psychosis in south London. PRiSM study 4. British Journal of Psychiatry, 171: 260-4

Phelan M, Stradins L, Morrison S (2001) Physical health of people with severe mental illness. $B M J ; 322$ : 443-4.

Pinfold V, Huxley P, Thornicroft G, et al (2003a) Reducing psychiatric stigma and discrimination. Evaluating an educational intervention with the police force in England. Social Psychiatry and Psychiatric Epidemiology, 38: 337-44.

Pinfold V, Toulmin H, Thornicroft G, et al (2003b) Reducing psychiatric stigma and discrimination. Evaluation of educational interventions in UK secondary schools. British Journal of Psychiatry, 182: 342-6.

Repper J, Perkins R (2003) Social Inclusion and Recovery. A Model for Mental Health Practice. Ballière Tindall.

Rethink (2005) Running on Empty. Building Momentum to Improve Well-Being in Severe Mental IIIness. Rethink.

Rose DS, Wykes TH, Bindman JP, et al (2005) Information, consent and perceived coercion: patients' perspectives on electroconvulsive therapy. British Journal of Psychiatry, 186: $54-9$
Rossi A, Amaddeo F, Bisoffi G, et al (2002) Dropping out of care: inappropriate terminations of contact with community-based psychiatric services. British Journal of Psychiatry, 181: 331-8.

Sartorius N (2002) latrogenic stigma of mental illness. BMJ; 324: 1470-1.

Shaw Trust (2006) Mental Health: The Last Workplace Taboo. Shaw Trust. Swanson GM, Ward AJ (1995) Recruiting minorities into clinical trials. Toward a participant-friendly system. Journal of the National Cancer Institute: 87: 1747-59.

Szmukler G, Appelbaum P (2001) Treatment pressures, coercion and compulsion. In Textbook of Community Psychiatry (eds G Thornicroft \& G Szmukler): 529-44. Oxford University Press.

Thornicroft G, Davies S, Leese M (1999) Health service research and forensic psychiatry. A black and white case. International Review of Psychiatry, 11: 250-7.

Thornicroft G, Tansella M, Becker T, et al (2004) The personal impact of schizophrenia in Europe. Schizophrenia Research; 69: 125-32.

Thornicroft G (2006a) Actions Speak Louder. Tackling Discrimination Against People with Mental IIIness. Mental Health Foundation.

Thornicroft G (2006b) Shunned. Discrimination Against People with Mental IIIness. Oxford University Press.

Ucok A, Polat A, Sartorius N, et al (2004) Attitudes of psychiatrists toward patients with schizophrenia. Psychiatry and Clinical Neurosciences: 58 89-91.

Wang PS, Berglund PA, Kessler RC (2003) Patterns and correlates of contacting clergy for mental disorders in the United States. Health Services Research; 38: 647-73.

Wang PS, Lane M, Olfson M, et al (2005) Twelve-month use of mental health services in the United States. Results from the National Comorbidity Survey Replication. Archives of General Psychiatry, 62: 629-40.

Wilkinson DG, Greer S, Toone BK (1983a) Medical students' attitudes to psychiatry. Psychological Medicine: 13: 185-92.

Wilkinson DG, Toone BK, Greer S (1983b) Medical students' attitudes to psychiatry at the end of the clinical curriculum. Psychological Medicine; 13: 655-8

Wittchen HU, Jacobi F (2005) Size and burden of mental disorders in Europe. A critical review and appraisal of 27 studies. European Neuropsychopharmacology, 15: 357-76.

World Health Organization (2005) Mental Health Atlas 2005. WHO.

\section{MCQs}

1 Evidence about public views of, and access to, psychiatric care suggests that

a the public believe mental health professionals are less helpful for treating schizophrenia than depression

b depression is the most treatable mental illness

c the majority of people with mental illness in the USA seek help

$\mathrm{d}$ when psychiatric care is readily available, many people prefer to avoid services for fear of being labelled as mentally ill

e Black groups receive less healthcare but have lower rates of mental disorders than White groups.

2 Evidence suggests that people with mental illness may avoid psychiatric services because they:

a do not want to waste the doctor's time

b fear they will be prescribed 'talking' treatments rather than tablets

c are afraid of psychiatric services because of adverse media portrayals d think they will get through it with the help of family and friends

e think they will not be taken seriously.

3 Evidence suggests that psychiatric healthcare professionals:

a are less pessimistic about the chances of recovery from mental illness than is the general population

b are often confident that their interventions will be successful

c rarely discourage their patients from a timely return to 'normal' life to prevent relapses

d may develop prejudicial attitudes towards certain patient groups while still in training

e do not allow their prejudicial attitudes towards certain patient groups to influence the quality of care they deliver.

\section{Mentally ill people:}

a are often satisfied with their treatment at the hands of psychiatric services

b who are also healthcare professionals receive better care than lay patients

c have a decreased risk of premature death compared with the rest of the population

$d$ are at risk of self-discharge with no further follow-up if they become dissatisfied with their treatment

e often feel they receive enough information about their condition from psychiatric services.

\section{Psychiatrists:}

a can make a significant impact on treatment and care by actively addressing all forms of stigma and discrimination against patients

b should have a standard way in which they offer diagnoses, explanations and advice to patients

c should always present the worst possible psychosocial outcome to patients when discussing their prognosis to avoid raising false hope

d should not provide too much information to patients who are likely not to fully understand

e should put less emphasis on psychological treatments for their patients. 